\title{
Embrace the change
}

\author{
With the accelerating pace of energy technology development and diffusion around the world, more \\ must be done to ensure that our electricity systems are able to adapt to current and future changes.
}

In recent weeks, three countries set new records for electricity source provision, while several companies and heads of state issued statements about plans for new energy technology implementation, illustrating that change in power systems isn't just in the air - it's happening all around us.

In the power sector, Portugal reportedly ran on $100 \%$ renewable sources for four consecutive days between 7 and 11 May (http://go.nature.com/FV7NmT). While prime weather conditions and network management performance contributed to the clean energy run, in recent years Portugal has also invested in more renewables capacity, in its dams to support variability of its wind through provision of hydroelectricity, and in energy efficiency measures to reduce demand. Doubtless we will see the country build on this milestone through the summer months and beyond.

That same week, the UK saw seven periods without any electricity provided by coal (http://go.nature.com/gtjZje) — allegedly the first time since coal-fired stations opened in the UK in 1882. Given the British government's stated intention to end the use of coal by 2025, this occurrence likely marks the beginning of the end for the fossil fuel. If these coal pauses become a trend then it is possible that the UK will completely remove coal from its electricity mix before that deadline. However, the continued uncertainty around the building of the new nuclear power reactor at Hinkley Point and the increasing concerns about supply adequacy (http://on.ft.com/1UQ2OgR) leaves room for doubt about how the government will be able to cope with its current reliance on aging plants and how it plans to meet the shortfall in the longer term.

A few days after coal began sputtering in Britain, Germany logged another important step in its Energiewende plan when on 15 May it provided significant portions of its electricity through renewables (http://go.nature.com/dPEjpp). At its peak, renewables supplied almost 100\% of demand. At several points in the day, electricity prices even turned negative.

Elsewhere, off-shore wind received a boost from the news that Statoil has been granted a seabed lease to build the world's largest floating wind farm off the coast of Peterhead in Scotland (http://go.nature.com/Ao36bA). Somewhat ironically, Peterhead was previously the intended site for a carbon capture and storage project until the UK government cancelled its funding for such schemes in late 2015. Although still relatively young, floating wind farms can operate in waters too deep for conventional off-shore facilities. This allows them to tap into otherwise inaccessible resources. If proven successful, the technology could be replicated in many other regions of the world with currently only limited wind power availability, like Japan.

Meanwhile, the home storage revolution continues apace, particularly in Australia where demand for solar and storage installations are rapidly increasing. As part of a trial, SA Power Networks - South Australia's monopoly network provider - is now offering customers large discounts on rooftop solar and storage systems in a bid to defer investment in grid upgrades and expansion (http://go.nature.com/BxHAb4). It's a potentially risky move, but one that allows SA Power Networks to experiment with the operation and business model for decentralized electricity provision, to find optimal outcomes for both consumers and power generators, and to understand how its grids may evolve in the future.

Further grid-balancing measures are also underway in the UK, where the National Grid and Nissan recently announced a new scheme allowing electric vehicle owners to sell electricity from their car's battery back to the grid (http://on.ft.com/1WXQIT0). Such vehicle-to-grid schemes have been under discussion in different parts of the world for some years, though with only very limited implementation so far. The UK project will allow the National Grid to draw power from vehicles connected to specific charging points when demand is high, charging them again later when demand is low.

The UK is also hoping to position itself at the forefront of modern transport technology, with intentions to increase investment in autonomous vehicles (http://go.nature.com/cLEeGj). At the same time, advocacy group Securing America's Future Energy called on the US government to enable further roll-out and future adoption of autonomous vehicles by removing regulatory barriers and increasing support around liability in case of accidents (http://go.nature.com/UsbHNB). Driverless vehicles are considered with scepticism by many, despite their promise of more efficient, safer, cleaner transport. Coupled together with a vehicle-to-grid scheme like Nissan's, the efficiency and flexibility gains could be very large for the country, although at this preliminary stage it's hard to say what impact they'll have on the UK's capacity concerns - especially with electric vehicle ownership expected to rise in the future.

Examples like the above - all from May alone - do not yet demonstrate that national electricity systems can function purely from renewables or that our reliance on fossil fuels has dissipated. The records set in Europe are, for the time being, isolated events in the middle of wider system change, while much of the technology under discussion remains preliminary.

But these announcements do highlight the increased prominence of renewable sources and new technologies in our power supply and the difficulties being encountered by fossil fuels like coal. They also highlight the rapid shift in technology that is occurring, where increasing affordability and consumer preference means adoption is rising fast. As a result, we need to ensure that systems providing our power are able to keep up - not just by having the capacity available to supply demand at affordable prices, but also the tools to respond to disruption from aging infrastructure and to intermittency.

More flexibility built in to regulation will allow networks to adapt to this rapidly changing technological environment and to engender innovation in response to that change. At the same time, better pricing structures and tariffs are needed that reflect the new landscape. In particular, it is increasingly vital to combat possible inequities in billing as the rise of rooftop solar, storage and electric vehicles shift the burden of centralized provision away from those causing increasing costs of the system and onto those less able to pay for it.

It's increasingly clear that we shouldn't be wondering about when we will have distributed systems - we have them now. With an outlook premised on continual change, we must be willing and able to embrace it. 